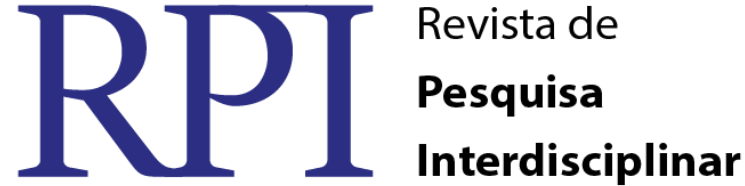

\section{ASPECTOS SIGNIFICATIVOS NO ENSINO DAS CIÊNCIAS NATURAIS: UMA EXPERIÊNCIA NO ENSINO FUNDAMENTAL}

\author{
Angleib Justino Figueiredo de Freitas - UEPB \\ Gustavo de Alencar Figueiredo - UFPB
}

\begin{abstract}
Resumo:
Com o objetivo de analisar os aspectos epistemológicos inseridos no Ensino de Ciências Naturais, explicitando sua orientação teórico-metodológica e suas aplicações e implicações práticas, o presente trabalho buscou permear os aspectos que permeiam a relação Ensino-Aprendizagem que se desenvolve na escola Dom Moisés Coelho, no município de Cajazeiras - PB e os sujeitos para desenvolvimento do tema e da pesquisa foram à professora do Componente Curricular de "Ciências" do Ensino Fundamental e os/as estudantes da referida turma. Através das observações, e análises fundamentadas na leitura de diversos autores na literatura educacional, constatamos que a prática docente que estava sendo desenvolvida pela professora não se mostrou satisfatória, pois se apoiou num ensino fragmentado e descontextualizado, abrindo espaço, assim, para um "déficit" na construção de conhecimentos científicos por parte dos/as estudantes. Verificamos o distanciamento dos pressupostos construtivistas que anunciam a tendência da Pesquisa em Ensino de Ciências no que concerne a relação Ensino-Aprendizagem. A investigação também mostrou que através da intervenção de uma prática pedagógica contextualizada, apoiada nos moldes de um trabalho epistemológico inserido no Ensino de Ciências, os/as estudantes puderam corresponder significativamente no que diz respeito à aprendizagem dos conteúdos trabalhados pelo bolsista, embasado pela orientação de diversos aspectos sobre o tema: ensino de Ciências Naturais. As discussões promovidas no trabalho oferecem condições para que os alunos compreendam os assuntos estudados, bem como as relações estabelecidas entre os conteúdos direcionados a uma contraposição ao uso de regras memorísticas e livrescas que pouco contribuem paro o desenvolvimento da aprendizagem dos/as estudantes na escola.
\end{abstract}

Palavras-Chave: Ensino-Aprendizagem, Ciências Naturais, Epistemologia.

\section{ASPECTS SIGNIFICANT DEVELOPMENTS IN TEACHING NATURAL SCIENCES: AN EXPERIENCE IN ELEMENTARY SCHOOL}

\begin{abstract}
In order to analyze the epistemological aspects inserted in the Natural Science Education, explaining its theoretical and methodological guidance and its application and practical implications, this study sought to permeate the aspects that permeate the teaching-learning relationship that develops in the school Don Moses Coelho in the city of Cajazeiras - PB and subjects for theme development and research were the Curriculum Component professor of "Science" of the 9th year of elementary school and / the students of that class. Through the observations, while fellow of Introduction to Teaching the PIBID, and analyzes based on reading several authors in the educational literature, we found that the teaching practice that was being developed by the teacher is not satisfactory, because it supported a fragmented and decontextualized teaching, open space, so for a "deficit" in the construction of scientific knowledge on the part of / the students. We found the distance of constructivist assumptions announcing the trend of Research in Science Teaching regarding the teaching-learning relationship. The research also showed that through the intervention of a contextualized pedagogical practice,
\end{abstract}


supported along the lines of an epistemological work inserted in Science Teaching, the / the students were able to significantly match with regard to the learning of the contents worked by grantee, based for guidance various aspects of the subject: teaching Natural Sciences. The discussions held in the job offer conditions so that students understand the subjects studied, as well as the relations between the content directed to a contrast to the use of memorísticas and bookish rules do little stop the development of the students in school learning.

Keywords: Teaching and Learning, Natural Sciences, Epistemology.

\section{INTRODUÇÃO}

Este trabalho se justifica pela importância da reflexão sobre a metodologia e os aspectos significativos inseridos na relação Ensino-Aprendizagem no ensino das Ciências Naturais no âmbito do Nível Fundamental, uma vez que é nessa etapa escolar que os/as alunos/as começam a observar e a "ter contato com a Ciência propriamente dita". Com relação a tais aspectos, os/as professores/as têm se deparado com situações cada vez mais conflitantes dentro da sala de aula, seja por mais condições de trabalho, desinteresse e apatia dos alunos ou práticas pedagógicas que não satisfaçam a demanda por um ensino significativo e satisfatório

Cabe salientar a necessidade de ruptura com os modelos ou práticas reprodutivistas ou mecanicistas que não levam em consideração os aspectos Epistemológicos na relação EnsinoAprendizagem, que no geral, não estão inseridos no Ensino das Ciências Naturais no plano do Ensino Fundamental. Para Delizoicov (2007, p. 177), Epistemologia "é a área da filosofia que estuda o conhecimento". Apoiado no contexto epistemológico, a interação entre aluno e aprendizagem torna-se mais significativa, pois o conteúdo é entendido como algo que se constrói ao longo do tempo, que tem origem, que se modifica, e dessa maneira, traz significado para os mesmos.

Somando-se aos problemas existentes na relação Ensino-Aprendizagem, observamos como resultado a formação de alunos que são incapazes de dominar e aplicar o conhecimento científico que aprendem nas escolas, pois o conteúdo que é ensinado, está permeado por diretrizes que visam apenas a memorização de conceitos prontos para a aprovação dos testes e provas.

RPI Revista de Pesquisa Interdisciplinar, Cajazeiras, v. 1, Ed. Especial, 168 - 177, set/dez. de 2016. 
No que podemos considerar e constatar no ensino das Ciências Naturais, os estudos concluem que é necessário enfatizar os aspectos epistemológicos que corroboram para um ensino dinâmico e significativo, apoiados na concepção de Ciência como atividade humana, social e historicamente construída. Assim:

O desafio de pôr o saber científico ao alcance de um público escolar em escala sem precedentes - público representado, pela primeira vez em nossa história, por todos os segmentos sociais e com maioria expressiva oriunda das classes e culturas que até então não freqüientaram a escola, salvo exceções - não pode ser enfrentado com as mesmas práticas docentes das décadas anteriores ou da escola de poucos e para poucos (DELIZOICOV, 2007, p. 33).

Para o desenvolvimento dessas competências, devemos nos apoiar no conceito de que a construção do conhecimento se dá através da análise e domínio dos fenômenos da esfera científica, rodeadas por conceitos epistemológicos que, dão ênfase e apoio lógico para que o/a aluno/a possa discutir e reproduzir o conhecimento já produzido sempre que possível.

\section{O/A Professor/a e o Conteúdo}

Um dos aspectos cruciais para o ensino de Ciências Naturais diz respeito aos conteúdos. É neste referencial que a metodologia se apóia para, que o processo de ensinoaprendizagem seja satisfatório que propicie condições adequadas para que o/a aluno/a não perca o foco das atividades desenvolvidas na sala de aula.No entanto, a maioria dos professores ainda conduzem suas aulas guiados por um senso comum pedagógico do que pelos conhecimentos científicos e didático-pedagógicos construídos ao longo da sua formação.

De acordo com Carvalho (2004, p.109)

O professor de Ciências precisa ter REFERÊNCIAS na Ciência, se se quer que seu discurso seja marcado pelas características da Ciência. A construção dessa referência pode ser dada por meio da abordagem histórica. [...] Além disso, conhecer o passado das idéias e buscar compreender a transformação delas pode ajudar a entender a Ciência como um recorte da realidade que se relaciona com outras atividades humanas, com outros diferentes recortes dessa realidade.

RPI Revista de Pesquisa Interdisciplinar, Cajazeiras, v. 1, Ed. Especial, 168 - 177, set/dez. de 2016. 
É dentro desse paradigma que o/a professor/a deve apoiar o seu discurso a fim de que o/a mesmo/a tenha domínio sobre o conteúdo a ser ministrado, propiciando referencias sobre recortes históricos, culturais e sociais sempre que exigido. Corroborando com Carvalho (2004, p. 106-107):

A história da Ciência, [...] contempla o estudo das ciências com seus aspectos sociais, humanos e culturais. [...] conhecer o contextos de produção, saber como se deu a elaboração de um conceito ao longo do tempo e que discussões foram travadas até ele se consolidar facilita a compreensão desses conceitos.

Uma maneira de selecionar e organizar os conteúdos a serem abordados são pelos temas estruturadores. Esses permitem o desenvolvimento de um eixo central com objetos de estudo, conceitos, linguagens, habilidades e procedimentos próprios, embora estejam inseridos em grande parte dos conteúdos, é necessária uma sistematização acerca dos mesmos, pois:

\begin{abstract}
Todo texto didático de Ciências traz em si a concepção de ensino de seus autores, bem como a concepção de Ciência que eles têm. Um livro de Ciências [...] precisa apresentar explicitamente a preocupação com alguns aspectos fundamentais para à construção da Ciência como uma atividade humana, histórica, culturalmente determinada, cujos empreendimentos visam construir explicações racionais do mundo. (MACHADO, 2009, p.76)
\end{abstract}

Dessa maneira, o/a professor/a tem de estar dotado de autonomia na escola em que atua, a fim de que não seja acometido por situações que visem sufocar a sua prática pedagógica, influenciando diretamente nas suas atitudes. Nesse aspecto, é necessário que ele/elar não se limite ou fique refém do Livro Didático, pois de acordo com Delizoicov (2007, p.36-37):

\begin{abstract}
Ainda é bastante consensual que o livro didático (LD), na maioria das salas de aula, continua prevalecendo como principal instrumento de trabalho do professor, embasando significativamente a prática docente. Também os espaços de divulgação científica e cultural, como museus, laboratórios abertos, planetários, parques especializados, exposições, feiras e clubes de ciência, fixos ou itinerantes, não podem ser encarados só como oportunidades de atividades educativas complementares ou de lazer.
\end{abstract}

RPI Revista de Pesquisa Interdisciplinar, Cajazeiras, v. 1, Ed. Especial, 168 - 177, set/dez. de 2016. 
Não obstante, artigos, revistas e textos didáticos são importantes subsídios para uma prática pedagógica significativa, desde que esses sejam requisitados com responsabilidade e dotados de caráter didático e cientifico.

\section{A Aula: um espaço para Reflexão}

A aula é o momento de interação entre professor/a e aluno/a, de debate entre ambas as partes acerca do conteúdo, espaço não para tirar dúvidas, mas de produzi-las e, assim, dinamizar o ensino e a aprendizagem. Dependendo dos modos, sejam eles didáticos, metodológicos e epistemológicos, a aula pode tornar-se num momento agradável ou não.

No início do ano letivo, os/as alunos/as estão eufóricos/as, ansiosos/as e dispostos/as. Todavia, em seu final, apresentam-se cansados/as e desmotivados/as. Como isso é possível se para a grande maioria deles/as que não repete de ano -, sentindo-se, portanto, curiosos/as com relação aos novos conteúdos nunca vistos antes e que induzem às suas atenções - passam a se sentir cansados e desmotivados com os conteúdos do final do ano, uma vez que, também revestem-se de caráter inovador?

É evidente que a maioria das práticas educativas nas escolas brasileiras carece de artifícios metodológicos que satisfaçam uma demanda cada vez mais esta inserida numa sociedade capitalista, excludente do ponto de vista social, que sufoca as relações pessoais num modelo extremamente competitivo. Parafraseando Cortella (2008, p. 85):

Uma das questões cruciais para nossas praticas pedagógicas é a concepção sobre o conhecimento dentro da sala de aula; no mais das vezes, o conhecimento é entendido como algo acabado, pronto, encerrado em si mesmo, sem conexão com sua produção histórica.

As atividades desenvolvidas na sala de aula devem levar em consideração o/a aluno/a como ponto de partida e de chegada para que a aprendizagem seja realmente significativa e satisfatória, de acordo com (Cortella, 2008, p.102): a criação e recriação do conhecimento na escola não esta apenas em falar sobre coisas prazerosas, mas principalmente, em falar prazerosamente sobre as coisas.

RPI Revista de Pesquisa Interdisciplinar, Cajazeiras, v. 1, Ed. Especial, 168 - 177, set/dez. de 2016. 
Sob essa ótica, o/a professor/a tem de assumir o seu papel de mediador/a, ou seja, direcionar efetivamente o seu trabalho à sua profissão, porque se ele/ela desenvolve sua atividade com bom senso, conseqüentemente sobra entusiasmo, vontade e comprometimento com sua atividade, visto que, muitos não proporcionam condições para uma aprendizagem significativa a seus/suas alunos/as, com métodos realmente eficazes, uma vez que, é notório que eles/elas permanecem desmotivados e apáticos.

No que concerne a tal prática, o/a professor/a abre espaço para métodos avaliativos que terminam por mascarar a aprendizagem do aluno. Assim, Cortella, (2008, p. 117) enfatiza que "ceitar, a priori, a impossibilidade do trabalho sem todas as condições é condenar ainda mais ao fracasso aqueles que já estão exauridos".

Não, podemos somente atribuir o fracasso escolar aos/às professores/as, visto que eles/elas "não podem encarar sua tarefa específica como um empreendimento solitário. A perspectiva de uma capacitação inteiramente externa, que ignore as potencialidades da própria equipe escolar é desmobilizadora". É necessário que esse agente, então, procure desenvolver sua atividade da melhor maneira possível em contraponto a todas as adversidades que assolam a realidade escolar e, dessa maneira, ele/ela proporcionará condições adequadas para exercer sua atividade pedagógica.

Com o avanço da Ciência, os conteúdos têm de ser trabalhados de uma maneira em que o/a aluno/a sinta-se sujeito atuante na sua aprendizagem e que possa tornar-se sujeito ativo na comunidade em que vive ou em qualquer lugar em que ele atuar, agindo conscientemente frente aos conflitos que permutam uma sociedade extremamente dependente da Ciência e da Tecnologia.

\section{A Prática Docente}

Um dos maiores problemas na temática do ensino está na questão da metodologia, ou seja, no modo como a mesma é aplicada ou se está correspondendo com as exigências da relação implícita entre aluno e conteúdo. O professor muitas vezes se depara com situações que exigem uma flexibilidade além do seu alcance para satisfazer às exigências que lhe são inerentes, pois de acordo com (Pozo \& Crespo, 2009, p.19): 
Essa deteriorização da educação cientifica se traduz, também, em uma suposta queda nos níveis de aprendizagem dos alunos, em uma considerável desorientação entre os professores diante da multiplicação das demandas educacionais que precisam enfrentar (novas disciplinas, novos métodos, alunos diversificados, etc.) e, em geral, uma defasagem crescente entre demandas formativas dos alunos, especialmente a partir da adolescência, e a oferta educacional que recebem.

Dentro de apenas uma classe, existe um ambiente bastante diversificado do ponto de vista sócio-cultural. É notória a quantidade de alunos/as que têm suas próprias opiniões, idéias conceitos, dúvidas e que exigem uma resposta rápida e eficaz por parte do/a professor/a, ocasionando muitas vezes, um mal estar para o mesmo frente uma classe cheia, quando suas respostas não satisfazem as perguntas que lhe são direcionadas.

É necessário que o/a professor/a procure "homogeneizar" o quanto possível à prática direcionada a seus alunos/as, pois toda aprendizagem precisa ser significativa estes/as, ou seja, deve estar relacionada com seus conhecimentos, experiências e vivencias, permitindolhes formular problemas e questões de interesse; entrando em confronto experimental com problemas práticos relevantes, e transferindo o que aprendeu para outras situações da vida. Se sua prática fracassa, encontramos problemas demasiadamente desagradáveis, pois:

A disciplina em sala de aula é hoje o maior problema, seguido de muito perto pela falta de motivação. Não se pode dissociar um do outro - aliás, é quase impossível afirmar quem é causa ou consequiência. Em geral, o aluno se torna indisciplinado quando pára de aprender. (ZAGURY, 2006, p. 84).

Outro aspecto que podemos observar na sala de aula é, o crescente número de "objetos de lazer" portáteis que os/as alunos/as se distraem. Quando não gosta da aula, da matéria ou do/a professor/a, liga seu celular, aparelho de música - mp3, rádio - celular com internet, DVD portátil, dentre outros e vão se distrair com assuntos midiáticos ou coisas que lhes parecem prazerosas. Ainda segundo Zagury ( 2006, p. 95),

Se a família não atua ou não sabe como atuar para colocar a escola como prioridade, $[\ldots]$ ou ainda se se deixou seduzir pelos valores da sociedade de consumo, os alunos fatalmente considerarão que o compromisso com a aprendizagem não é essencial.

RPI Revista de Pesquisa Interdisciplinar, Cajazeiras, v. 1, Ed. Especial, 168 - 177, set/dez. de 2016. 
Essa temática tem de ser trabalhada e orientada no sentido de tentar sanar ao máximo os problemas que corriqueiramente repercutem dentro da sala de aula, pois "as formas de aprender e ensinar são uma parte da cultura que todos devemos aprender e sofrem modificações com a própria evolução da educação e dos conhecimentos que devem ser ensinados". (POZO \& CRESPO, 2009, P. 23).

\section{A Avaliação}

A avaliação constitui aspecto primordial no processo de Ensino-Aprendizagem, uma vez que é à partir da mesma que o/a aluno/a é questionado/a acerca das suas curiosidades epistemológicas e posto à prova sobre os conteúdos que foram ministrados. A tendência dominante e quase exclusiva é a de que ele/ela seja avaliado/a por modelo meramente ilustrativo que não garante uma avaliação realmente significativa, pois está apoiada num contexto que visa apenas à memorização de exercícios e conceitos trabalhados em classe.

De acordo com Cortella (2008, p. 119) "a finalidade da avaliação na escola é identificar problemas e facilidades na relação Ensino-Aprendizagem de modo a reorientar o processo pedagógico". Diversos/as professores/as já se depararam com a seguinte situação: os/as alunos/as reclamaram da avaliação porque o que eles/elas mais estudaram não foi o que caiu na prova. Então desse ponto de vista, a avaliação que visava apenas à memorização não considerou o aluno da maneira mais justa!

Nesse sentido, Hoffmann (2007, p. 31) chama a atenção para o fato de que "é preciso ter clareza de que as aprendizagens dos alunos são de dimensões diferentes para se realizar um trabalho eticamente responsável”. A avaliação se constrói não só por uma prova escrita, mas por diversos olhares, como ainada afirma Hoffmann(2007, p. 32), “o/a professor/a não pode se limitar a observar passivamente, mas interpretar, dar sentido àquilo que vê, reconstruir a realidade viva do/a aluno/a (decifração)".

Então, seguindo essa linha, a própria aula é objeto de avaliação, pois quando o/a aluno/a participa, questiona, interage, ele/ela está sendo sujeito atuante e pode ser avaliado também sobre o ponto de vista das suas ações positivas em sala que de acordo com referida autora:

RPI Revista de Pesquisa Interdisciplinar, Cajazeiras, v. 1, Ed. Especial, 168 - 177, set/dez. de 2016. 
Todos os alunos, de todas as idades, reagiram positivamente e de imediato a essa atenção, mudando rapidamente de atitude, revelando maior comprometimento com suas tarefas e seus avanços, dando demonstrações de afeto por quem lhe dedicou cuidados e respeito. (HOFFMANN (2007, P. 35)

Podemos constatar a qualidade da avaliação sob o ponto de vista do diálogo, do questionamento, da liberdade de expressão, pois este momento reflexivo abre espaço para que o aluno sinta-se à vontade no processo e ensino-aprendizagem.

\section{À guiza de Conclusão}

Os resultados apresentados sugerem que os métodos empregados, explicitados em cada tópico que se seguiu, estabeleceram um modelo metodológico baseado na construção do conhecimento levando-se em consideração o/a aluno/a como agente ativo na relação EnsinoAprendizagem. Dentro desse aspecto, é interessante ressaltar o quanto os/as alunos/as se sentiram motivados/as quanto a novos critérios metodológicos frente a um ensino fragmentado que não oferece ferramentas para se desenvolver uma prática com conjuntura e qualidade.

Nesse sentido, podemos observar que a prática pedagógica do professor/a se desenvolve com trabalho, pesquisa e um planejamento que realmente vise o/a aluno/a como foco principal para o seu resultado, ressaltando os aspectos que norteiam o ensino como uma ferramenta eficaz de mudança de atitude dos nossos jovens frente a um mundo completamente burocrático e competitivo.

\section{REFERÊNCIAS Bibliográficas}

CORTELLA, MARIO Sergio. A Escola e conhecimento: fundamentos epistemológicos e políticos. $12^{\circ}$. ed. São Paulo: Cortez, 2008.

CARVAlHO, Ana Maria Pessoa de. Ensino de Ciências: Unindo a Pesquisa e a Prática. São Paulo: Thonsom, 2004.

DELIZOICOV, Demétrio; ANGOTTI, José André; PERNAMBUCO, Marta Maria. Ensino de Ciências: fundamentos e métodos. São Paulo: Cortez. 2007.

HOFFMANN, Jussara. O jogo do contrário em avaliação. $3^{\circ}$. ed. Porto Alegre: Mediação, 2007.

RPI Revista de Pesquisa Interdisciplinar, Cajazeiras, v. 1, Ed. Especial, 168 - 177, set/dez. de 2016. 
MACHADO, Nilson José. Educação: competência e qualidade. Coleção Ensaios Transversais, 37.São Paulo: Escrituras, 2009.

POZO, Juan Ignacio. CRESPO, Miguel Ángel Gómez. A Aprendizagem e o Ensino de Ciências: Do Conhecimento Cotidiano ao Conhecimento Cientifico. $5^{\circ}$. ed. Porto Alegre, Artmed, 2009.

ZAGURY, Tania. O Professor Refém: para pais e professores entenderem por que fracassa a educação no Brasil. 4º edição, Rio de Janeiro: Record. 2006. 